\title{
O MITO DE INÊS E A VISÃO DO SÉCULO XIV
}

Geysa Silva

Universidade Federal de Juiz de Fora

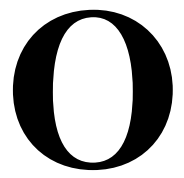

tempo medieval que, em suas origens, assiste ao encontro de povos e civilizações em estágios desiguais de desenvolvimento, tem como principal característica a "violência da vida". Não se discutirão aqui os vários conceitos de feudalismo defendidos por diferentes escolas historiográficas; apenas se quer destacar que o feudalismo não se desenvolveu por igual em toda a Europa, e foi particularmente singular na Península Ibérica, onde os laços entre o rei e a nobreza conseguiram permanecer muito fortes. Tradicionalmente o século XIV é visto como marco do declínio do feudalismo. Observe-se que este foi um período de crises, atravessado pelas grandes chuvas (1315), pela Grande Fome (1315 a 1317) e pela Peste Negra (1348). A conseqüência imediata desses fatos foi um enfraquecimento da população, um contraste acentuado entre saúde e doença, alegria e tristeza. É ainda uma época em que se fugia da realidade pelo abandono do mundo ou pelo sonho: pela via religiosa ou pela via política.

É nesse clima religioso e sensual que se passa a história de Inês e Pedro: participaram do poder e por ele foram perseguidos; gozaram o prazer e pagaram cara por ele atingidos pela morte, nela encontraram perenidade. O amor de Inês e Pedro pode, então, ser apreciado sob o ponto de vista da História, ou do mito. Quer na primeira, quer na segunda hipótese, essa história transcende seus problemas numa universalidade que ultrapassa qualquer tempo.

Os laços de sangue, os ressentimentos entre famílias, as rivalidades, a paixão amorosa, a função mediadora, mas nem sempre edificante do clero, tudo isso transporta o homem contemporâneo 
para um Portugal do passado, ainda muito preso às tradições medievais, todavia prestes a entrar na modernidade.

No mito de Inês de Castro pode-se sempre observar a ambigüidade do amor medieval com seu duplo poder de ternura e sedução. Inês é apresentada com a marca da pureza, apesar de um amor adúltero: como no amor cortês, a dama escolhida nada tinha a ver com o casamento. Ela continua inacessível, mesmo depois que suas relações com Pedro lhe dão três filhos, pois jamais seu amor é aceito publicamente, nem consegue, em vida, tornar-se rainha. Inês viveu numa sociedade que descobria, em tudo, sinais de decadência; era moda condenar os tempos ou vivê-los intensamente. Enquanto os nobres procuravam gozar a vida, as ordens mendicantes lembravam aos fiéis o fim sombrio que poderiam ter e a arte religiosa reiterava a presença da morte em gravuras de madeira, representando a decrepitude final

A partir de investigações sobre o modo de vida do século XIV, toda a problemática da diferença entre amante e esposa acaba se impondo de maneira surpreendente por quantos se aproximam do mito. Inês, ao reforçar essa diferença, exige da corte que o critério de reconhecimento de uma ligação sexual não seja diluído pelos mexericos palacianos, nem fundado na instituição religiosa; provoca, então, novas questões pela simples força de sua rebeldia às velhas respostas. Insiste em ocupar seu lugar de amante do príncipe, não de maneira clandestina e secundária, porém procura ela mesma criar essa posição e sua atividade política é central a esse processo. Inês abre toda uma nova dimensão para as amantes reais e é difícil apreendê-la inicialmente, porque essa jovem galega incorpora-a ao que se pode considerar como uma explicação esquemática de sua condenação: a notória ligação com Castela e a ameaça de uma guerra civil.

Ao apreciar a história de Inês vê-se que, de um modo geral, os membros da corte tinham noção da realidade em que viviam, por isso não tentavam modificar suas existências e, sim, ordená-las. Pensavam que a vida comporta sempre o bem e o mal e julgavam 
que aqueles, que propunham a igualdade (mesmo entre os gêneros), concorriam para a desordem. No imaginário português do século XIV, Inês aparece como a figura que tenta desembaraçar-se do pecado, viver seu amor terreno como se estivesse no Éden e, insensatamente, forçar a mão de Deus. Assim, pervertia os simples, incentivava a desobediência ao rei e aos bispos, feria as hierarquias.

Inês era filha bastarda, portanto, já nascera com o estigma do ilícito, fruto da transgressão. É verdade que essa era uma situação banal, tão banal que ninguém se importava em saber de que escolha resultara aquele nascimento. ${ }^{1}$ Porém, a realidade da configuração social, com sua maneira prática e jurídica de classificar as pessoas, encaixava-as em lugares pré-determinados. Inês despreza essa classificação, procura aumentar seu espaço, busca um meio de realizar seus desejos, vive um amor dionisíaco que impressiona a todos e pressiona o rei a afastá-la da corte. As atribuições políticas e a peste que atormentaram esse pequeno universo forçaram uma sólida aliança entre o rei e seus súditos; para preservá-la, D. Afonso IV não hesitará em punir os rebeldes, nem que seja necessário verter o sangue humano. Com uma Lisboa cheia de castelhanos que tinham vindo com D. Constança ou fugido do cruel Pedro I, a situação portuguesa torna-se preocupante.

A figura de Inês aparece como uma ameaça a um edifício equilibrado, estabelece uma confusão de papéis sociais e é responsável pela dúvida que percorria a corte. Pedro casara secretamente? A paixão de Inês se torna, então, subversiva. Isso pode parecer estranho, pois ela era apenas uma dama estrangeira; nos Paços de Santa Clara, vive praticamente na solidão e seu poder material se apresenta minúsculo. Onde estaria o perigo? As atitudes

\footnotetext{
${ }^{1} \mathrm{Na}$ Crônica de El Rey D. Afonso IV, escrita por Ruy de Pina (1653), encontrada na Biblioteca Nacional de Lisboa, seção de "Portugaliae Monumenta Historica", é possível ler a linhagem de D. Inês. Assim, tem-se: "Inês de Castro era filha de D. Pedro Fernando de Castro, chamado o da guerra e de sua favorita, D. Aldonça Nunes Chacim, (...) ", Vol. I, p.22.
} 
de Inês mostram que o desejo tem seus próprios valores e o amor carnal outros critérios de distinção social e política que podem ser antagônicos aos critérios vigentes. Ousa aceitar (legal ou ilegalmente?) o amor de um príncipe, nivelar posições, sonhar com a igualdade. Ignora que, para o clero, ela permanece em pecado; para a nobreza, há a necessidade de restabelecer a hierarquia, o poder do rei e afastar a amante incômoda. É por isso que várias cartas régias são expedidas e tenta-se afastá-la de Portugal.

O conflito toma proporções desmesuradas, o medo da condenação e o apetite amoroso entram em choque; a conduta de Pedro e Inês torna-se inexplicável, derrama-se na loucura e termina no crime. Inês encontra o rancor dos nobres, escudados numa virtude que nem sempre praticavam. Ao desprender-se dos deveres que a uniam à comunidade portuguesa, assume os riscos da liberdade e as instituições vão estremecer por efeito da autoconsciência dessa mulher: ela sacode os laços constituintes da Igreja e do Poder real e acha-se com o direito de agir e sentir. Ignora a hipocrisia das vinculações, porque está a transgredi-las; desconhece fins políticos que não sejam os seus próprios.

Quando se examinam os documentos relativos à vida de Inês, tem-se impressão de que ela age como se tivesse o poder de uma feiticeira. Torna-se madrinha de D. Luis, irrita as monjas de Santa Clara, incita o príncipe a pretender o trono de Castela. Persiste em ficar em Portugal, mesmo quando recebe ordens para não o fazer e essa persistência a destrói. Em oposição frontal a Inês está D. Afonso IV; ambos, todavia, estão corretos em suas posições - Inês porque defende os direitos que existem além do religioso e do político, D. Afonso IV porque representa os direitos do Estado. Tal como Antígona e Creonte, esses dois personagens se complementam e englobam o domínio da tragédia.

Inês é trágica porque recusa qualquer concessão que a afaste de seus objetivos. Se o Destino começa sua tragédia ao despertar o interesse de Pedro, é ela quem a leva avante e passa a realizar seu próprio desígnio. Entretanto, Inês não queria morrer e percebe-se 
que sempre desejara a vida, por isso implora por ela até o fim, e usa os filhos para comover o rei. Deve ter sentido, em algum momento, que seus interesses eram por demais variados e que não tinha possibilidade de viver uma existência inteiramente diferente da habitual, pois no terreno da transgressão as normas parecem adquirir maior rigidez.

Para dignificar a figura de Pedro, o mito deu-lhe a qualidade de justiceiro, e a História, o aposto - o Cru. Esse príncipe, que conseguira desfazer-se da primeira mulher e que humilhara a segunda com a presença ostensiva da amante, não consegue protegê-la, envolvido que está com suas caçadas e montarias. Pedro, ainda que seja um paradoxo, desempenha o papel de filho obediente, pois na verdade só começa a agir após a morte do pai. Então fica pronto para tudo: para a vingança, o traslado, o anúncio do casamento.

Não há dúvida de que Pedro gosta de fazer o papel de justiceiro. Ao mostrar-se implacável, Pedro se envolve na tarefa de moralizar as ações de seus súditos e tranqüilizar a própria consciência. É claro que o mito dramatizou muitas de suas atitudes que só se tornaram interessantes porque lhes foi emprestada uma certa teatralidade.

Pedro é produto de sua cultura, de uma sociedade que aceitava como verdadeiros certos valores terríveis, considerados necessários à manutenção de sua ordem. Ele se torna trágico, porque é uma figura melancólica que sente uma inclinação sentimental irrealizável e uma pessoa moralmente dividida, por demais complexa para que possa ser admirada ou condenada. Quanto a Inês, apesar de tudo o que foi escrito sobre a Rainha, sua vida permanece um enigma, como convém a qualquer motivo poético, pois não permite afirmações decisivas, estimula adivinhações, excita a fantasia e refugia-se no imaginário de cada um que a procura.

Cada poeta, que vai no encalço do mito, dele faz uma nova leitura e quase sempre subverte o que já havia sido dito anteriormente. Então, o mito, longe de fechar-se, não faz outra coisa senão abrirse para múltiplas visões, embora se conservem as eqüivalências de sentido. Pode-se dizer que, no mito de Inês, a produção abrange o 
confronto homem/amor/morte e celebra, à sua maneira, o papel mediador da linguagem.

A poesia transforma a violência do sacrifício de Inês num protesto contra o autoritarismo do poder real e, através de sua imagística, se torna a ponte de passagem para uma experiência que revela as possibilidades verbais com que os mitos são construídos. Pedro e Inês tornam-se universais quando suas vidas servem para demonstrar que o amor é maior que a morte e que o respeito pela existência humana é fundamental na preservação da liberdade. O macabro nessa história é que o mito fez com que se aceitasse, de maneira simpática, os carrascos de Inês. As mortes de Álvaro Gonçalves e Pero Coelho, de maneira ultrajante, acabaram por criar, em torno deles, um halo de piedade que fez com que fossem aceitas humanamente. Pedro, ao ordenar a vingança, tornou-a o mais abominável possível e o resultado foi um acontecimento dramático em que o vingador é visto como desprezível. O assassinato de Inês era coisa do passado, os nobres não tinham acabado de matá-la, por isso os motivos de Pedro estavam esvaziados. A verdade é que a trajetória do mito é extremamente complexa e só estudos detalhados sobre o assunto poderiam dar uma idéia de seus meandros.

Assim, a transcrição literária do mito de Inês, tanto em Os Lusíadas como em Castro, dá uma ênfase ao desespero, que põe em evidência a contradição entre o infinito do querer e a própria finitude do homem. E o amor de uma dama bastarda por um príncipe já traz em si seu limite e sua condição. O que se vê, quer no poema épico, quer no dramático, é uma luta das personagens para preencher o vazio que encontram em torno de si, tarefa essa destinada ao fracasso, porque a insuficiência humana não permite sua realização. Camões e Antônio Ferreira mostram que o desespero não é alienante, muito ao contrário, é o motor que vai impulsionar a História. É o que veremos em Os Lusíadas e Castro. 


\section{- Inês e Os Lusíadas}

Por mais que se saiba da grandiosidade de Camões, mesmo que se conheça bem sua produção poética, a releitura do episódio de Inês de Castro, no Canto III de Os Lusíadas, é sempre impressionante. Entre tantos que trataram o tema da rainha, Camões mostra a arte mais lírica e estabelece com o leitor um contato tão emotivo, que tem atravessado o tempo. O leitor não apenas se emociona com seus versos como dificilmente poderá esquecê-los, especialmente quando narra:

O caso triste e digno de memória

Que do sepulcro os homens desenterra.

Aconteceu da mísera e mesquinha

Que depois de ser morta foi rainha. ${ }^{2}$

Apesar de pretender uma grande orquestra das proezas lusitanas, Camões é um miniaturista, tem a habilidade de inserir um detalhe, que às vezes define um personagem ou uma situação. É assim que dá ênfase a um quotidiano comum, composto de incertezas e ansiedades amorosas. Gradualmente, para ancorar a história no tempo, começa a construir o painel daqueles dias, num crescendo que impõe o tema do desespero. Usa a imagem do homem como joguete do Destino, demonstra que Eros é indiferente às desgraças e faz a evocação perfeita da relação do homem com o trágico, como se nada pudesse fugir ao espanto e à dor: "Naquele engano de alma, ledo e cego/ Que a Fortuna não deixa durar muito./"

Camões representa os sentimentos de Inês (a saudade da separação ou o desespero diante da morte), interessando-se por algo mutável como a própria vida e fazendo do amor a encarnação da beleza, do mundo ordenado e feliz.

De noite, em doces sonhos que mentiam,

De dia, em pensamentos que voavam,

E quanto, enfim, cuidava e quanto via,

Eram tudo memória de alegria. ${ }^{3}$

${ }^{2}$ CAMÕES, [s.d.]. p.308.

${ }^{3}$ CAMÕES, [s.d.]. p.312. 
Há uma tranqüilidade nostálgica, em que a felicidade já não é vivência, mas recordação; o Príncipe não é presença, mas lembrança. A solidão é a tônica de um mundo prestes a desmoronar-se. O emprego do imperfeito do indicativo vai contrastar com as estrofes seguintes; o tempo verbal predominante é uma sucessão de presentes, e a tragédia de Inês eclode nos versos em que a violência, de início iminente, acaba por concretizar-se. Pedro "Os desejados tálamos enjeita"; D. Afonso IV "tirar Inês ao mundo determina/ Por lhe tirar o filho que tem preso". Narrado em vinte estrofes (da estrofe 118 até a estrofe 137) o episódio tem seu ponto alto na estrofe 127 (a décima), exatamente no meio da história, com os versos
Ó tu que tens de humano o gesto e o peito
(Se de humano é matar uma donzela)
Fraca e sem força, só por ter sujeito
O coração a quem soube vencê-la. ${ }^{4}$

É pungente esse desespero de quem não se negou ao prazer e respondeu ao gesto de encontro que lhe fora oferecido. A força da fala de Inês, pedindo clemência, está em conseguir que o passado deixe de ser passado, algo distanciado no tempo, para assumir o estatuto do agora, a mesma carga explosiva do presente. Mostra que a única resposta para a vida é o exercício da sobrevivência, mesmo quando essa já está definitivamente perdida.

Numa sociedade em que a morte não era coisa tão terrível, Camões surpreende com seu libelo contra a injustiça, na defesa de uma vida dedicada ao amor, que acabou por ser destruído, e resgata a atitude das moças de Coimbra que conseguem a sobrevivência de Inês dando o nome de Fonte dos Amores a uma fonte nas vizinhanças do Choupal.

O texto de Camões exige uma leitura demorada. O discurso expande amor e sofrimento, numa linguagem colorida de adjetivos, ao lado de frases apositivas e perguntas retóricas. Aqui, entretanto,

${ }^{4}$ CAMÕES, [s.d.]. p.316. 
a linguagem se revela mais intimista que nos outros cantos. E é neste sentido que se identifica com os sentimentos humanos, mostra a contraface do poeta épico:

Quem viu um olhar seguro, um gesto brando

Uma suave e angélica excelência,

Que em si está sempre as almas transformando,

Que tivesse contra ela resistência. ${ }^{5}$

É claro que nenhum poeta resiste ileso às releituras das gerações seguintes, contudo ainda permanece a beleza desses versos que, embora cuidadosamente eruditos, não têm um sabor acadêmico excessivo. E apesar do vocabulário precioso e da sintaxe rebuscada, a apreciação do espírito original de Camões ainda consegue emocionar seus leitores. A emoção provém principalmente do recurso dramático que Camões introduz no episódio, quando Inês se dirige a D. Afonso IV. O discurso direto realça o tema do desespero, uma vez que a "personagem" esgota seu potencial de comover, antes que chegue ao fim o último ato de sua existência. A paixão de Inês é um fato singular que só pode ser compreendido na medida em que é dramatizado. Se fosse apenas narrada, não atingiria todo seu vigor, seu estado de transfiguração. É o drama que favorece simultaneamente um recolhimento e uma expansão do ser, o falar e o calar-se, na convergência do íntimo com a teatralidade.

O desespero, plenamente dramatizado, é o que se verá em Castro.

\section{- A dramaticidade de Castro}

A tragédia, filha dileta da Grécia, não é apenas produto de autores bem sucedidos na chamada Antigüidade Clássica. Ao contrário, ela tem atravessado os tempos e acaba sempre aparecendo em diferentes épocas, inclusive nos dias atuais, apesar de suas

${ }^{5}$ CAMÕES, [s.d.]. p.326. 
limitações: uma predestinação e um desejo desmedido. Antônio Ferreira parte de um fato histórico e constrói um drama que aponta para um determinado tempo social e político: no caso, o declínio medieval na Península Ibérica. Sabe-se que o trágico nasce com a crise da Grécia tribal que desapareceu sob a origem da pólis. Édipo, Ifigênia e Antígona são heróis de um mundo que se esfacelou e representam a verdade mítica que estava sendo substituída pela verdade racional. Assim também Inês, que surge numa época de crise para um povo cuja consciência nacional fora precocemente sentida, em razão da Reconquista.

Castro realiza o movimento essencial da tragédia, que é a destruição do protagonista, provocada por sua "hybris". Sem "hybris" nenhum personagem é destruído; sem ser destruído, o personagem não consegue alcançar o divino, tornar-se um demônio. "Hybris", portanto, é uma coisa ambígua, que conduz a caminhos opostos: à danação e ao estado de graça, mas a graça poderá ou não ser concedida.

A tragédia seria inconcebível se os melhores fossem os mais fortes, pois não se pode sentir a perda quando não há nada significativo a ser perdido. Antônio Ferreira, entretanto, não inclui vilões em seu drama. Os nobres que matam a Castro não aparecem como carrascos e sua força, movida por motivos bem humanos, é dramaticamente menor que o poder ligado à fraqueza da vítima.

Antônio Ferreira nos apresenta uma Castro atingida pela volúpia do sonho. O sonho necessário de Eros de realizar o amor, de experimentar no prazer a essência humana. Castro vive uma realidade angustiante que se fecha sobre ela desde as primeiras páginas. Sua insolência está em agir como se tivesse vivido uma tragédia quando, na verdade, esta ainda a esperava.

O autor tem uma compreensão do destino que é uma mistura de conceito grego com o terror diante dos atos implacáveis do deus do Antigo Testamento: "Pois tão he o bom Príncipe: Sol nosso/, Com cuja luz nos vemos e seguimos? A justiça que aos céus nos vay levando./". O instrumento do destino são os conselheiros do rei que decretam a morte da Castro. 
O problema focalizado desde a primeira cena é a necessidade que tem a Castro de ver seu amor aceito pelo Rei; esse é seu objetivo, seu ideal último de mulher e de heroína dramática. O drama se move neste sentido e, à medida que a não-aceitação desse amor se torna evidente, o desespero se apossa da personagem que vê seu mundo, o mundo do sentimento, caminhar para a destruição: "Socorra-me, ó Deus, e socorrei-me/ Vós, moças de Coimbra. Homes, que vedes/ Esta inocência minha, socorrei-me".

O tom confessional de suas extensas falas, quase monólogos, apresenta o doloroso processo de auto-conhecimento de uma identidade feminina obcecada pelo objeto de seu desejo; apreende o significado da paixão e a certeza de possuir o segredo do prazer, o reinado soberano do corpo:

Castro: Cos olhos lhe acendi no peito fogo.

Fogo que sempre ardeo, e inde arde agora

$\mathrm{Na}$ primaveira vivez inteiro, e puro.

Por mim lhe aborreciam altos estados

Por mim os nomes de princesas grandes

Por tam grande me avia nos seus olhos. ${ }^{6}$

Ao introduzir o Infante apenas no primeiro e no último ato, Antônio Ferreira reitera a omissão do príncipe e o engano da Castro. A ausência sugere que o Infante evita situações em que não deseja tomar parte, o que contradiz suas próprias palavras: "Vive segura, lança os medos fóra,/ Que antes morte que vida sem ti quero".

A introdução do coro que, segundo a tradição, é elemento original da tragédia, mostra a preocupação de Antônio Ferreira em seguir os modelos clássicos. Este coro permanece acima da "realidade" dos personagens; por sua boca fala a sabedoria inconteste, pois o coro não tem interlocutores. A realidade do coro é a realidade religiosa, sancionada pelo mito. Ele se une às personagens, por vezes em tom invocativo; reconhece a onipotência do Grande Pai e reitera o contraste entre a verdade dos sentimentos e o mundo das

${ }^{6}$ FERREIRA, [s.d.]. p.24. 
aparências; a oposição entre as forças da natureza e os interesses da cultura, expressos na luta entre prazer e poder. O coro se identifica com as personagens para atingir a essência das coisas; não vê no erro um mal absoluto. Ele sabe que ao experimentar o prazer, o homem adquire um forte desejo de viver que se manifesta em seus atos, mesmo quando estes são interditos ou fogem à lógica do explicável.

Coro I: Amor em doces cantos,

Em doces liras soe,

Torne seu brando nome est'ar sereno.

Fujam mágoas e prantos.

O lédo prazer, voe,

E claro o rio faça o valle ameno.

No terceiro ceo toe

D'amor a doce lira,

E de lá te coroe,

Castro, d'ouro o grã Deos, que amor inspira. ${ }^{7}$

As falas adquirem um tom de lamento; e os cortes bruscos, efetuados pelo coro, fazem parte de uma intenção anti-discursiva, de um discurso que interrompe os diálogos e fragmenta-os de maneira áspera, tal como o universo flagrado e deflagrado pelo autor. Aliás, é a partir da tensão entre o tema da morte como índice de poder e seu tratamento dramático que Antônio Ferreira alcança plenamente o poético.

A grande característica de Castro é que ela encerra uma duplicidade entre a derrota e a esperança. Daí o tom marcante, sempre melancólico de sua fala. Na multiplicidade de uma só vida, Antônio Ferreira procura agrupar o tormento de uma existência que é designada pela morte.

Castro: Como não crias e sabia? Ama, fuge

Fuge desta ira grande, que nos busca

Eu fico, fico só mas inocente. ${ }^{8}$

${ }^{7}$ FERREIRA, [s.d.]. p.48-49.

${ }^{8}$ FERREIRA, [s.d.]. p.82. 
A desgraça da Castro é apenas o epílogo da história de um desejo comovente, do capricho de um infante que se transforma num sentimento arrebatador e leva o príncipe e a jovem dama a viverem um "grande desvario", no paroxismo do amor-paixão.

\section{Conclusão}

Entre o fim do tempo medieval e a explosão renascentista há um tempo peculiarizado pela construção de imagens-símbolos: Heloísa, Beatriz, Inês. Camões e Antônio Ferreira surgem a conjurar livre e violentamente os estilhaços de um mundo, com vistas a um novo cosmos. Ao representar a morte, o pranto e o desespero, eles nos mostram os entrechoques das conturbações espirituais e dos desacertos do destino.

Na fugacidade do episódio de Inês, acumula-se um sentido não visível que lhe assegura a permanência, enquanto o nível visível da existência é atingido pela destruição. A morte de Inês, transformada em motivo literário, supera a temporalidade; ocorrida no século XIV, cria uma ordem em que, do século XVI ao século XXI, o passado é capaz de perdurar, deixar de ser transitório. Em ambos os textos, de Camões e de Antônio Ferreira, há um nãoconformismo com a contingência, com a história que se esgota na situação passageira e não remete a coisa nenhuma.

Ao tratar do mito de Inês, a literatura mostra um lado secreto, sufocado pela História, que converteu a vida da Rainha em fracasso. É claro que cada uma das obras escritas a seu respeito é parcial, cristaliza determinados aspectos em detrimento de outros. Entretanto essa parcialidade é sempre remetida à força configuradora dos mitos que cada poeta ou dramaturgo traz dentro de si. Desta forma Inês expressa a ordem do mundo, incongruente e fragmentada. Embora imortalizada em pedra, no túmulo de Alcobaça, a literatura não deixa que Inês se petrifique. Experimenta-se como processo, puro devir. Produz símbolos que variam por sua diferença e formam um universo inventivo, sempre em expansão, onde, por contágio, retoma-se o mito já em curso. 


\section{Bibliografia Geral}

BATAILLE, Georges. L'érotisme. Paris: Minuit, 1957.

BESSA LUÍS, Agustina. Adivinhas de Pedro e Inês. Lisboa: Guimarães \& Cia., 1983.

CAMÕES, Luís Vaz de. Os Lusíadas. Rio de Janeiro: Tecnoprint, [s.d.]. FERREIRA, António. Castro. 6.ed. Porto: Domingos Barreira, [s.d.]. FRYE, Northrop. Anatomia da crítica. Trad. Péricles Eugênio da Silva Ramos. São Paulo: Cultrix, 1973.

GRIMAL, Pierre. Dictionnaire de la Mythologie grecque et romaine. Paris: PUF, 1986.

HUIZINGA, Johann. O declínio da Idade Média. Trad. Augusto Abelaira. São Paulo: EDUSP, 1978.

LE GOFF, Jacques. La civilización del occidente medieval. Trad. J. de Serra Fáfols. Barcelona: Editorial Juventud, 1969.

MATTOSO, José. A nobreza medieval portuguesa, a família e o poder. Lisboa: Editorial Estampa, 1981.

NIETZSCHE, Friedrich. A origem da tragédia. Trad. Rubens Rodrigues Torres Filho. São Paulo: Abril Cultural, 1983.

REIS, Carlos. O conhecimento da literatura - Introdução aos Estudos Literários. Coimbra: Almedina, 1974.

STAIGER, Emil. Conceitos fundamentais da poética. Trad. Celeste Aída Galeão. Rio de Janeiro: Tempo Brasileiro, 1972.

VERNANT, Jean-Pierre. As origens do pensamento grego. Trad. Isis Borges B. da Fonseca. São Paulo: Difel, 1984.

\section{Bibliografia Específica}

ACENHEIRO, Cristóvão Rodrigues. Chronica dos Senhores reis de Portugal. Lisboa: Academia Real das Sciencias de Lisboa, 1824; tomo IV. 
JESUS, Frei Rafael de. Monarquia Lusitana. Lisboa: Arquivo Nacional Português, 1983.

LOPES, Fernão. Crónica do Senhor dom Pedro, oitavo rei destes regnos. Lisboa: Academia Real das Sciencias de Lisboa, 1816.

MARTINS, A. C. La fatalité dans la Castro de Ferreira. Bulletin d'Histoire du théâtre portugais. Paris: Arquivos do Centro Cultural Português, Université Paris II, 1969.

PINA, Ruy de. Chronica de El Rey Dom Afonso IV. Lisboa: Biblioteca. Academia Real das Sciencias de Lisboa, 1653.

SOUSA, Maria Leonor Machado de. D. Inês e D. Sebastião na literatura inglesa. Lisboa: Presença, 1980.

\section{Resumo}

Este trabalho se propõe a analisar o amor entre Inês de Castro e D. Pedro I transformado em tema poético. Procura-se enfatizar alguns aspectos que, enfatizados em verso, levaram a uma dupla explicação: de um lado o conjunto de elementos que formam a história revela arquétipos do amor medieval; de outro, o sacrifício de Inês, efetuado como punição de um crime, revela índices da violência do poder.

\section{Resumé}

Ce travail se propose d'analyser l'amour parmi Inês de Castro et D. Pedro I. On a cherché à mettre en relief certains aspects qui, ressortant particulièrement dans les versions en vers, conduisent à une double explication: d'un côté, l'ensemble des éléments qui composent l'histoire se relie aux archétypes de l'amour medyen, d'autre côté, le sacrifice d'Inès, accompli comme punition d'un crime, manifeste des indices de la violence du pouvoir. 